\title{
Conservation Agriculture: An Efficient Tool to Overcome the Drawbacks of Conventional Agricultural System towards Sustainable Crop Production
}

\author{
Saju Adhikary ${ }^{1 *}$, Benukar Biswas ${ }^{1}$ and Anjali Priya ${ }^{2}$ \\ ${ }^{1}$ Deparment of Agronomy, Bidhan Chandra Krishi Viswavidyalaya \\ ${ }^{2}$ Department of Agricultural Chemistry and Soil Science, Bidhan Chandra Krishi \\ Viswavidyalaya, Bidhan Chandra Krishi Viswavidyalaya, Mohanpur, \\ Nadia741252, West Bengal, India \\ *Corresponding author
}

\begin{abstract}
A B S T R A C T
Conservation Agriculture (CA) consists of the practical application of three interlinked principles, that is no or minimum tillage, mulching of soil surface and crop species diversification, in conjunction with other complementary agricultural practices of integrated crop production. In India several efforts have been made to develop, refine and disseminate conservation agricultural technologies for the past two decades and have made significant progress even though there are several constraints that affect adoption of CA. The technologies used in CA benefit the environment, increase crop diversification, improve efficient use of resources, save water and nutrients, increase yields, and provide opportunity to reduce the cost of production. However, there are several constraints for promotion of CA technologies, such as lack of appropriate seeders especially for small and medium farmers, unavailability of skilled and scientific manpower burning of crop residues, competition of crop residues between their usage in CA and livestock feeding, and overcoming the biased mindset about tillage. This article reviews the emerging concerns due to adoption of conventional agriculture systems, and analyses the constraints and research needs for improvement of conservation agriculture in India.
\end{abstract}

\section{Keywords}

Conservation agriculture,

Conventional agriculture,

Constraints,

Resource use efficiency, Tillage

Article Info

Accepted:

11 June 2020

Available Online:

10July 2020

\section{Introduction}

The major challenges before most of the Asian countries are attaining food security for the growing population, alleviating poverty while sustaining agricultural systems under the current scenario of depleting natural resources, alleviating the negative impacts of climatic variability, spiraling cost of inputs and volatile food prices. In addition to these 
challenges, there are several other constraints indicating non-sustainability of agricultural systems including soil erosion, soil organic matter content reduction, and soil salinization. These are caused mainly due to: (1) intensive tillage causing soil organic matter reduction, soil structural degradation, soil compaction, surface sealing and crusting, reduced water infiltration rates, water and wind erosion,(2) insufficient return of organic material back to the soil and (3) monocropping. Therefore, a change in farming practices pattern is important which can be opted through elimination of unsustainable conventional agriculture practices such as, excessive ploughing/tilling the soil, removing all organic material and monoculture is crucial for maintaining future productivity while sustaining the natural resources. Conventional agricultural practices consist of extensive soil tillage, burning of crop residues and external inputs leading to soil degradation through loss of organic matter, soil erosion and compaction. In India more than $70-75 \%$ farmers are small land holders and are major contributors in total food production but they are still using traditional farming practices. Most of the farmers give little attention to the long term management of natural resources and can rarely afford inputs such as good quality seeds and fertilizers, herbicides for chemical weed management, and heavy machineries. Conservation agriculture is targeted to (i) attain high and sustained production levels,(ii)achieve acceptable profits, and (iii) conserve the environment (FAO, 2009). It further argues that conservation agriculture is based on enhancing natural biological processes occurring both above and below the soil surface which goes beyond the scope of zerotillage and therefore provides a range of technology and management options. Conservation agriculture practices are applicable to all the crops, including cereals, horticulture and plantation crops. However, these are more popular in rice, wheat, maize, and soybean. The conservation agriculture practices promises tremendous potential for use in different soils and agro-ecological systems. These are independent of size of land holdings but their adoption is most urgently required by smallholder farmers to save resources, reduce their cost of production, and increase profit (Derpsch, 2008). The scarcest input to smallholder farming is farm power that is required for land preparation, crop establishment, weeding, harvesting and transport. Conservation agriculture is practiced to reduce and eliminate the need for land preparation for crop production. CA promotes most soils to have a richer bioactivity and biodiversity, a better structure, and high natural physical protection against weather (raindrops, wind, dry or wet periods). Soil erosion is therefore highly reduced, soil agronomic inputs slightly reduced, while pesticide biodegradation is enhanced. It protects surface and ground water resources from pollution and also mitigates negative climatic effects. Hence, CA provides excellent soil fertility, saving money, time and fossil-fuel usage. So, it is an efficient alternative to traditional agriculture, attenuating its drawbacks.

\section{Definition of conservation agriculture}

Conservation agriculture is a crop management system that maintains soil cover through surface retention of crop residues with no /zero till and reduced tillage. $\mathrm{CA}$ is described by FAO (http://www.fao.org.ag/ca) as a concept of agricultural crop production which is based on resource saving by enhancing the natural and biological processes above and below the ground. As per Dumanski et al., (2006) conservation agriculture (CA) is not "business as usual", based on maximizing yields while exploiting the soil and agro-ecosystem resources rather 
is based on optimizing yields and profits, to achieve a balanced agricultural, economic and environmental benefits. It advocates that the combined social and economic benefits gained from combining production and protection of the environment, including reduced input and labor costs, are greater than those from production alone. With CA, farming communities have become providers of healthy living environments for the wider community through reduced usage of fossil fuels, pesticides, and other pollutants, and through conservation of environmental integrity and services. As per FAO definition $\mathrm{CA}$ is to 1) attain high and sustained production levels, 2) achieve acceptable profits, and 3) conserve the environment. It aims at reversing the process of degradation caused due to the conventional agricultural practices like intensive agriculture, burning/removal of crop residues. It can be referred as a resource efficient or resource effective agriculture which aims at conserving, improving and making efficient use of natural resources through integrated management of available soil, water and biological resources in combination with external inputs.

\section{Principles of conservation agriculture}

Conservation agriculture practices followed in many parts of the world are based on ecological principles adopting sustainable land use (Wassmann, 2009; Behera et al., 2010; Lal, 2013). Adoption of CA is the need of the hour as a powerful tool for management of natural resources for enhancing resource use efficiency (RUE) and crop productivity to achieve sustainability in agriculture. Conservation agriculture basically relies on 3 interlinked principles which must be considered together for appropriate designing, planning and implementation processes. These are:

\section{Minimal mechanical soil disturbance}

The soil biological activity provides stable soil aggregates having varied amounts of macro and micro pores allowing air movement and water infiltration. This process can be called "biological tillage" and it is incompatible with mechanical tillage. With mechanical soil disturbance, the biological soil structuring process is stopped. Minimum soil disturbance maintains optimum proportions of gases in the root zone, porosity for water movement, retention and release, moderate organic matter oxidation, and limits the re-exposure of weed seeds and their germination (Kassam and Friedrich, 2009).

\section{Permanent organic soil cover}

A permanent soil cover is important to protect the soil from the deleterious effect of exposure to rain and sun, to provide a constant supply of food to the micro and macro organisms in the soil and alter the soil microclimate favourable for optimal growth and development of soil organisms, including plant roots which in turn improves soil aggregation, soil biological activity, soil biodiversity and carbon sequestration (Ghosh et al., 2010).

\section{Diversified crop rotations}

The rotation of crops is not only necessary to offer a diverse nutrient supply to the soil microorganisms, but also for exploring and recycling different soil layers for nutrients that have been leached to deeper layers. Crops diversity in rotation leads to a diverse population of soil flora and fauna. Cropping sequence following rotations with legumes helps in biological nitrogen fixation, minimal rates of build-up of pest species population through life cycle disruption, control of offsite pollution and enhancing biodiversity (Kassam and Friedrich, 2009; Dumanski et al., 2006). 
Table.1 Extent (' $000 \mathrm{ha}$ ) of adoption of CA worldwide by Major five country in 2008/09, 2013/14 and 2015/16

\begin{tabular}{|c|c|c|c|c|}
\hline SI No. & Country & CA area 2008/09 & CA area 2013/14 & CA area 2015/16 \\
\hline $\mathbf{1}$ & USA & $26,500.00$ & $35,613.00$ & $43,204.00$ \\
\hline $\mathbf{2}$ & Brazil & $25,502.00$ & $31,811.00$ & $32,000.00$ \\
\hline $\mathbf{3}$ & Argentina & $19,719.00$ & $29,181.00$ & $31,028.00$ \\
\hline $\mathbf{4}$ & Canada & $13,481.00$ & $18,313.00$ & $19,936.00$ \\
\hline $\mathbf{5}$ & Australia & $12,000.00$ & $17,695.00$ & $22,299.00$ \\
\hline
\end{tabular}

Source: Derpsch et al., (2018)

Table.2 Cropland area under CA (M ha) by region in 2015/16; CA area as \% of global total cropland, and CA area as \% of cropland of each region

\begin{tabular}{|c|c|c|c|}
\hline Region & $\begin{array}{c}\text { CA Cropland } \\
\text { area }\end{array}$ & $\begin{array}{c}\text { Per cent of global CA } \\
\text { cropland area }\end{array}$ & $\begin{array}{c}\text { Per cent of Cropland area } \\
\text { in the region }\end{array}$ \\
\hline South America & 69.90 & 38.7 & 63.2 \\
\hline North America & 63.18 & 35.0 & 28.1 \\
\hline $\begin{array}{c}\text { Australia and } \\
\text { New Zeland }\end{array}$ & 22.67 & 12.6 & 45.5 \\
\hline Asia & 13.93 & & 4.1 \\
\hline Russia and & 5.70 & 3.7 & 3.6 \\
\hline Ukraine & & & 5.0 \\
\hline Europe & 3.56 & 2.0 & 1.1 \\
\hline Africa & 1.51 & 0.8 & 12.5 \\
\hline Global total & 180.44 & 100 & \\
\hline
\end{tabular}

Source: Derpsch et al., (2018)

Status of conservation agriculture in India and abroad

Globally, CA is being practiced on about $180,438.64$ ha (Table 1). The major CA practicing countries are USA $(43,204.00 \mathrm{ha})$, Brazil (32,000.00 ha), Argentina (31,028.00 ha), Canada (19,936.00 ha) and Australia (22,299.00 ha). In India, CA adoption is still in its initial phase. Over the past few years, the major $\mathrm{CA}$ based technologies being adopted is zero-till (ZT) wheat in the ricewheat (RW) system of the Indo-Gangetic plains (IGP). The conventional agriculture 
based crop management systems are gradually undergoing a shift in model from intensive tillage to reduced/zero-tillage operations in other crops and cropping systems. In addition to ZT, other concepts of CA need to be included in the system to enhance and sustain the productivity as well as to exploit new sources of growth in agricultural productivity. The CA adoption also offers scope for diversification through crop intensification in RW cropping system by following relay cropping of sugarcane, pulses, vegetables etc. as intercrop with wheat and maize. The CA based resource conservation technologies (RCTs) help in integrating crop, livestock, land and water management research. In India, efforts to adopt and promote conservation agriculture technologies have been underway for nearly a decade but in the last 8-10 years these technologies are finding acceptance by farmers. Efforts to develop and spread conservation agriculture have been made through the combined efforts of ICAR institutes, several State Agricultural Universities, and the Rice-Wheat Consortium for the Indo-Gangetic Plains. The spread of technologies is taking place in India in irrigated Indo-Gangetic plains where ricewheat cropping systems predominate. Conservation agriculture systems have not been tried in other major agro-ecological regions like rainfed semi-arid tropics and the arid regions of the mountain agro-ecosystems.

\section{Benefits of conservation agriculture}

The benefits of conservation agriculture can be seen at national, regional and farm level. The benefits can be classified into three broad categories: (i) agronomic benefits that improve soil productivity; (ii) economic benefits that improve the production efficiency and profitability; and (iii) environmental benefits that make agriculture more sustainable.
Some of the benefits of conservation agriculture are listed below

Improve the sustainability of different production systems.

Provides soil as a sink for carbon dioxide, thereby improves soil organic carbon content and contributes in reducing global warming. Conservation agriculture is now receiving global focus for its carbon sequestration potential. It has been estimated that the total potential for soil carbon sequestration by agriculture could reduce about 40 per cent of the estimated annual increase in $\mathrm{CO} 2$ emissions (FAO, 2009). The emergence of carbon credit payments for the farmers practicing conservation agriculture is now being considered seriously and expected to further add to the income of those farmers who adopt it.

Improves water infiltration and thereby reduces run-off of surface and ground water and enhances ground water recharge.

Improves habitation of organisms, from larger insects to soil borne fungi and bacteria, which improve soil biological, physical and chemical properties, thereby contributing to increasing crop productivity.

Reduce cost of production (15-16 per cent) by saving energy, labor and water, thereby increasing farm income.

Enhance biodiversity and improves the value of environmental services.

Reduction in poverty and enhance food and nutritional security due to higher, more stable yields and lower food prices.

\section{Constraints for adoption of conservation agriculture}

There are several problems encountered during adoption of conservation agriculture. The most important is the mindset of the farming community who were educated 
extensively and convinced about the intensive agriculture and use of external inputs. In the past, farmers have realised huge economic benefits by intensive agriculture practices. A complete shift from intensive tillage to zero or minimal tillage needs extensive educational programme by demonstrating the benefits accrued by conservation agriculture.

The second problem is related with the high cost of machines and implements. Farmers in the Indo-Gangetic plain are small and poor, thereby may not immediately shift from the existing available machines to the conservation agriculture machines.

The third problem is related to the access to information about conservation agriculture. Farmers need detailed information about tillage practices, different cultivation methods and use of improved varieties.

The fourth problem is related to skills development. New machines (zero till machine) and cultivation practices need skills development of the farmers. Agro ecological based conservation agriculture technologies are available, which need capacity of farmers to adopt and implement those in their production environment. Most of the farmers lack skills in using zero-till machines and cultivation practices that prevents adoption of conservation agriculture practices.

\section{Challenges in conservation agriculture}

Conservation agriculture as an upcoming paradigm for raising crops will require an innovative aspect to deal with management of varied, flexible and context specific needs of technologies. Conservation agriculture $R \& D$ (Research and Development), therefore will call for several innovative features to address the challenge. Some of these are:

Understanding the system - Conservation agriculture systems are more complex than conventional agriculture systems. The main limitation to the spread of CA system is lack of site specific knowledge (Derpsch, 2001). Efficient management of these systems will be highly demanding in terms of basic processes and interactions of components determining the performance of the whole system. For example, surface maintained crop residues act as mulch and reduce soil water losses through evaporation and maintain a moderate soil temperature regime (Gupta and Jat, 2010). However, at the same time crop residues act as a source of easily decomposable organic matter and could harbour pest populations. No-tillage systems will influence penetration depth and distribution of the root in the soil profile which, in turn, will influence water and nutrient uptake and mineral cycling. Therefore it is important to recognize conservation agriculture as a system and develop management strategies accordingly.

Building a system and farming system perspective - A system perspective is built by working in partnership with farmers. A group of scientists, farmers, extension workers and other stakeholders working in partnership mode will be critical in developing and promoting new technologies. This is somewhat different than in conventional agricultural $\mathrm{R} \& \mathrm{D}$, the system is to set research priorities and allocate resources within a framework, and little attention is given to building relationships and seeking linkages with partners working in complementary fields.

Technological challenges - While the basic principles forming the foundation of conservation agriculture practices, that is, no tillage and surface managed crop residues are well understood, adoption of these practices under different farming conditions is the major challenge. These challenges relate to 
development, standardization and adoption of farm machinery for seeding with minimum soil disturbance, developing crop management and harvesting systems.

Site specificity - Adapting strategies for conservation agriculture systems will be highly site specific. Learning across the sites will serve as a powerful tool in understanding why certain technologies or practices are effective in a set of situations and not effective in another set. This learning process will accelerate the building of a knowledge base for sustainable resource management.

Long-term research perspective Conservation agriculture practices, e.g. notillage and surface maintained crop residues result in resource improvement gradually therefore benefits come only after a time. In many situations, yield increase may not come in the early years of evaluation of impact of conservation agriculture practices. Understanding the changes and interactions among physical, chemical and biological processes is basic to developing improved soil-water and nutrient management strategies (Abrol and Sangar, 2006). Therefore, research in conservation agriculture must have long term perspectives.

In conclusion, history repeats itself. We witnessed a shift from organic to inorganic agriculture and now we are thinking about moving towards organic agriculture again. Similarly, earlier no-till system was followed which was replaced by an excessive till system, and from there to again no/minimum tillage system is being followed. Definitely, conservation agriculture has potential to improve the use efficiencies of natural as well as man-made resources, carbon sequestration and soil health (physical, chemical and biological). It improves the sustainability of the agricultural system by mitigating GHG emission and adapting to climate change.
However, the utilization/ exploitation of the CA practices needs to be optimized on the basis of different locations, crops and cropping systems based on sound benefit-cost economics. It needs interventions at all levels: by farmers, researchers, extension personnel and policy makers to analyse and understand how conservation theologies integrate with other technologies that promote CA. It is, therefore, a challenge for both the scientific community and farmers to overcome the past mindset and explore the opportunities that Conservation Agriculture offers towards sustainable agriculture development.

\section{References}

Abrol, I. P and Sangar, S. 2006. Sustaining Indian agriculture-conservation agriculture the way forward. Current Science, 91(8), 1020-2015.

Behera, U. K., Amgain, L. P and Sharma, A. R. 2010. Conservation agriculture: principles, practices and environmental benefits. In Behera, U. K., Das, T. K., and Sharma, A. R. (Eds.), Conservation Agriculture, 28-41.

Derpsch, R. 2001. Keynote: Frontiers in conservation tillage and advances in conservation practice. In Stott, D. E., Mohtar, R. H., and Steinhart, G. C. (Eds.), Sustaining the global farm. Selected papers from the 10th International Soil Conservation Organisation Meeting held May 24-29, 1999 at Purdue University and the USSA-ARS National Soil Erosion Research Laboratory.

Derpsch, R 2008. No-Tillage and Conservation Agriculture: A Progress Report in eds by Zoebisch, M.A., Y.T. Gan, W. Ellis, A. Watson and Sombatpanit, No-till Farming Systems S. Special Publication No 3, World Association of Soil and Water Conservation, Bangkok. 
Dumanski, J., Peiretti, R., Benetis, J., McGarry, D and Pieri. C.2006. The paradigm of conservation tillage. Proceedings of World Association of Soil and Water Conservation, P1, 58-64. Dumanski, J., Peiretti, R., Benetis, J., McGarry, D., and Pieri. C.2006. The paradigm of conservation tillage. Proceedings of World Association of Soil and Water Conservation, P1, 58-64. Food and Agriculture Organization of the United Nations (FAO). 2009, Conservation Agriculture. http://www.fao.org/ag/ca Rome, Italy.

Gupta, R and Jat, M. L. 2010. Conservation agriculture: addressing emerging challenges of resource degradation and food security in South Asia. In Behera, U.K., Das, T.K., and Sharma, A.R. (Eds.), Conservation Agriculture (pp.118). Division of Agronomy, Indian Agricultural Research Institute, New
Delhi - 110012, 216 p.

Kassam, A. H and Friedrich, T. 2009. Perspectives on Nutrient Management in Conservation Agriculture. Invited paper, IV World Congress on Conservation Agriculture, 4-7 February 2009, New Delhi, India.

Kassam, A., Friedrich, T and Derpsch, R. 2018. Global spread of Conservation Agriculture. International Journal of Environmental Studies, 1-23.

Lal, R. 2013. Climate-resilient agriculture and soil Organic Carbon. Indian Journal of Agronomy, 58(4), 440-450.

Wassmann, R., Jagadish, S.V. K., Sumfleth, K., Pathak, H., Howell, G., Ismail, A., Serraj, R., Redona, E., Singh, R. K and Heuer, S. (2009. Regional vulnerability of climate change impacts on Asian rice production and scope for adaptation. Advances in Agronomy, 102: 91-133.

\section{How to cite this article:}

Saju Adhikary, Benukar Biswas and Anjali Priya. 2020. Conservation Agriculture: An Efficient Tool to Overcome the Drawbacks of Conventional Agricultural System towards Sustainable Crop Production. Int.J.Curr.Microbiol.App.Sci. 9(07): 1333-1340. doi: https://doi.org/10.20546/ijcmas.2020.907.154 